\title{
Helicobacter pylori infection in patients with metabolic syndrome, with or without nonalcoholic fatty liver disease
}

\author{
Mohamed Rakha1*(D, Omayma Saleh', Mohamed S. Abdelgawad ${ }^{1}$ and Azza El Baiomy²
}

\begin{abstract}
Background: Helicobacter pylori (HP) infection is considered a risk factor of GIT diseases, e.g., gastric and duodenal ulcers and gastric carcinomas. It is transmitted through feco/oral route and can be diagnosed by many methods, e.g., stool antigen test (SAT). Metabolic syndrome (MET S) is considered a circle of metabolic derangements that can cause some complications as ischemic changes and heart diseases. Metabolic syndrome may also cause nonalcoholic fatty liver disease (NAFLD) resulting in liver fibrosis, cirrhosis, and HCC.

Results: The study included 300 subjects recruited from Obesity Clinic and Diabetes \& Endocrinology Unit, Specialized Medical Hospital, Mansoura University. Two hundred of metabolic syndrome patients were subdivided into two groups according to the presence or absence of NAFLD, in addition to 100 subjects not having metabolic syndrome and served as control group. We found that HP infection is more frequent in MET S with NAFLD patients (73\%) than in MET S without NAFLD (47\%) with $(P$ value $<0.001)$ emphasizing that HP infection increases the risk of NAFLD development in patients with MET S.

The study proved that HP infection is associated with increased degree of fibrosis significantly ( $P$ value $<0.001$ ) with progression to marked fibrosis which may complicate with NASH with over all predictive value of $75 \%$ especially in patients with hyperglycemia.

Conclusions: Our findings show that a circle of metabolic abnormalities seems to be attributed to HP infection in MET S patients increasing the risk of fatty liver and progression to marked fibrosis especially with coexistent hyperglycemia, dyslipidemia, and upper body obesity. Diagnosis and early eradication of HP infection will help in decreasing metabolic disturbances and possibility of NAFLD, and protect against marked fibrosis progression.
\end{abstract}

Keywords: Helicobacter pylori, Metabolic syndrome, Nonalcoholic fatty liver disease

\section{Background}

Helicobacter pylori (HP) infection was discovered in 1984 and considered as a possible risk factor for GIT diseases, e.g., gastric and duodenal ulcers and gastric malignancies. It is conveyed through feco/oral route [1]. Diagnosis of HP can be confirmed invasively through endoscope by gastric biopsies or non-invasively through

\footnotetext{
*Correspondence: mohamed_ad2007@yahoo.com

'Department of Internal Medicine, Faculty of Medicine, Mansoura University, Mansoura, Egypt

Full list of author information is available at the end of the article
}

stool antigen test (SAT) which is considered the most specific noninvasive method. Moreover, it is considered as a group I human carcinogen predisposing for gastric adenocarcinoma, as well as a risk factor for gastric mucosa-associated lymphomas [2]. HP infection not only affects proximal GIT (stomach and proximal duodenum), but there has also been growing evidence of its clinical consequences outside it in the distal luminal tract. Furthermore, extra intestinal derangements were detected [3].

\section{Springer Open}

(c) The Author(s). 2021 Open Access This article is licensed under a Creative Commons Attribution 4.0 International License, which permits use, sharing, adaptation, distribution and reproduction in any medium or format, as long as you give appropriate credit to the original author(s) and the source, provide a link to the Creative Commons licence, and indicate if changes were made. The images or other third party material in this article are included in the article's Creative Commons licence, unless indicated otherwise in a credit line to the material. If material is not included in the article's Creative Commons licence and your intended use is not permitted by statutory regulation or exceeds the permitted use, you will need to obtain permission directly from the copyright holder. To view a copy of this licence, visit http://creativecommons.org/licenses/by/4.0/. 
Nonalcoholic fatty liver disease (NAFLD) is defined as the presence of hepatic steatosis, either on imaging or biopsy, in the absence of a cause of secondary fat accumulation, such as significant alcohol consumption [4]. It is subdivided into two entities: simple nonalcoholic fatty liver (NAFL) or nonalcoholic steatohepatitis (NASH). Patients with NAFLD are generally asymptomatic, although they sometimes have organomegaly by abdominal examination or reveal mild elevation in liver enzymes on laboratory investigations; thus, NAFLD is often found accidentally, and it is considered as the hepatic insult of metabolic syndrome. Only through biopsy, simple steatosis can be differentiated from NASH [5]. Patients with NAFLD might progress from simple steatosis to steatohepatitis, then to fibrosis and cirrhosis [6].

Treatment of metabolic syndrome and NAFLD includes, as its mainstay, weight loss for those patients who are overweight. Meanwhile, decreasing liver enzymes' level and histological improvement can be reached by weight loss as well as increased physical activity [7].

The evidence for an association between HP infection and development of NAFLD has initially centered on the discovery of the presence of anti-HP immunoglobulin G (IgG) in patients with NAFLD. An initial study evaluating the presence of anti-HP IgG in 75 patients with suspected liver disease found that, anti-HP IgG was detected in the liver in one patient with NASH by PCR [8].

Subsequent studies, using PCR amplification for HP 16 srRNA genes in 46 patients with chronic liver disease, were able to identify HP 16 srRNA positivity in $45.4 \%$ (5/11) patients with NAFLD [9]. In fact, the authors demonstrated that HP infection (history of HP eradication and/or HP IgG seropositivity) could independently predict NAFLD in logistic regression analysis [10].

Metabolic syndrome refers to group of metabolic conditions that can lead to many complications as heart disease. The main features of metabolic syndrome are insulin resistance, high blood pressure, abnormal cholesterol levels, and increased risk for clotting. Previous researches showed that metabolic syndrome increases the risk of type II diabetes from 9 to 30 times, and the risk of heart diseases up to 4 times, than that of the normal population. Other health risks caused by metabolic syndrome include nonalcoholic fatty liver disease (NAFLD), resulting in inflammation and the potential for liver cirrhosis [11].

There are conflicting data regarding the association between HP infection and metabolic syndrome [12]. Also, there is limited number of studies focusing on the interaction between HP infection and NAFLD in patients with MET S.

\section{Aim of the work}

Given the high prevalence of HP infection in Egypt which is reaching up to $80 \%$ [13] and the relatively high prevalence of fatty liver [14], it could be significantly important to discover and establish the possible correlation between the two abovementioned factors especially in the presence of other metabolic disturbances of metabolic syndrome in the Egyptian patients.

\section{Methods}

Study design

It is a case control study.

\section{Study subjects}

The study included 300 subjects (18-65 years old) recruited from the Obesity Clinic and Diabetes \& Endocrinology Unit, Specialized Medical Hospital, Mansoura University.

Metabolic syndrome patients were selected according to the criteria of Alberti et al. [4] and subdivided into 2 groups according to the presence or absence of NAFLD, in addition to 100 subjects not having metabolic syndrome and served as control group.

- Control group: group 1, 100 age-matched healthy individuals.

- Metabolic syndrome (MET S) with NAFLD: group 2, 100 patients of MET S according to the criteria of Alberti et al. [4] with hepatic steatosis diagnosed by ultrasound.

- Metabolic syndrome (MET S) without NAFLD: group 3, 100 patients of MET S without NAFLD.

\section{Inclusion criteria}

1. Adult patients with age range 18-65.

2. Patients with metabolic syndrome: 3 or more of the following criteria [4].

- A waist circumference over $94 \mathrm{~cm}$ in men and over $80 \mathrm{~cm}$ in women

- Serum triglycerides $150 \mathrm{mg} / \mathrm{dl}$ or above, or taking medication for elevated triglycerides.

- HDL cholesterol $40 \mathrm{mg} / \mathrm{dl}$ or lower in men and $50 \mathrm{mg} / \mathrm{dl}$ or lower in women.

- Blood pressure of $130 / 85 \mathrm{mmHg}$ or above or taking medication for high blood pressure.

- Fasting blood glucose of $100 \mathrm{mg} / \mathrm{dl}$ or above or taking antidiabetic medications.

\section{Exclusion criteria}

1. Decompensated congestive heart failure, advanced renal or hepatic disease including $\mathrm{HCV}$, or malignancy including gastric carcinoma or hepatocellular carcinoma.

2. Active infections with antibiotic therapy. 
3. Other causes of fatty liver, e.g., fatty liver with pregnancy and TPN and history of alcohol intake.

4. Secondary obesity causes (Cushing and hypothyroidism syndromes).

5. Patients declining to provide informed consent.

\section{Patient evaluation}

All study patients were subjected to:

- History taking with stress on intake of medications, past history of antibiotic intake-history of H. pylori infection treatment.

- Thorough clinical examination with stress on blood pressure, weight, and height with measuring waist circumference and calculating BMI which was categorized as follows:

- Normal weight 18.5 to $24.9 \mathrm{~kg} / \mathrm{m}^{2}$.

- Overweight 25 to $29.9 \mathrm{~kg} / \mathrm{m}^{2}$.

- Obese more than $30 \mathrm{~kg} / \mathrm{m}^{2}$.

- Laboratory investigations:

Fasting lipid profile: LDL, HDL, TGs, cholesterol level; liver function tests: ALT/AST ratio; serum albumin; complete blood count (CBC); prothrombin time (PT); activated partial thromboplastin time (APTT); serum creatinine $(\mathrm{S} . \mathrm{Cr})$; thyroid-stimulating hormone $(\mathrm{TSH})$; fasting blood glucose (FBG).

- Abdominal ultrasonography for detection of hepatic steatosis

Increased echogenicity and brightness of liver parenchyma through visual assessment of hepatic echogenicity, measurements of the difference between the liver and kidneys in echo amplitude, evaluation of echo penetration into the deep portion of the liver, and determination of the clarity of blood vessel structures in the liver [15].

- NAFLD fibrosis risk score: calculated online-to discover patients with marked fibrosis-according to Angulo et al. [16] which divided the patients into the following:

1. NO or mild fibrosis (F0-F2).

2. Marked fibrosis (F3-F4) that might progress to $\mathrm{NASH}$

- H. pylori detection: stool antigen test (SAT).

H. pylori stool antigen tests were measured by using a one-step test device $(\mathrm{ABON})$ for the qualitative detection of HP Ag in the feces. The one step HP stool Ag test device $\mathrm{ABON}$ (Biopharm-Hangzhou) is a chromatographic immunoassay for the qualitative detection of HP antigen in human feces and providing results in 10 min with sensitivity and specificity more than 99.9\% [17].

According to the manufacturer's instructions, the test is defined positive if two distinct colored lines appear and negative if one line appears.

\section{Statistical analysis}

Data were fed to the computer and analyzed using the IBM SPSS software package version 22.0. Qualitative data were described using number and percent. They were described using median (minimum and maximum) for non-parametric data and mean and standard deviation for parametric data after testing normality using Kolmogorov-Smirnov test.

$P$ value less than 0.05 (5\%) is considered to be statistically significant.

Binary stepwise logistic regression analysis was used for prediction of independent variables of binary outcome. Significant predictors in the univariate analysis were entered into regression model using forward Wald method/Enter. Adjusted odds ratios and their 95\% confidence interval were calculated.

\section{Results}

The present study included 300 subjects. The average age of them ranges from 37 to 57 years old. One hundred and seventy-six cases were males and 124 cases were females (Table 1).

Results showed significantly higher values of body weight, BMI, waist circumference, and blood pressure in patients having MET $S$ with NAFLD than those without NAFLD $(P$ value $<0.001)$ (Table 2$)$.

Regarding lipid profile, TGs, s. cholesterol, and LDL levels were significantly higher in MET $S$ with NAFLD group versus MET $\mathrm{S}$ without NAFLD, while HDL level was significantly lower $(P$ value $<0.05)$.

Levels of ALT and FBG were significantly higher in NAFLD patients than non-NAFLDs $(P$ value $<0.05)$. S. creatinine level showed non-significant change (Table 3).

Prevalence of HP infection in all study population was 57.7\% (173 positive patients out of 300 using stool antigen test). HP infection was more frequent in MET S patients than controls. HP positive cases were significantly more frequent in MET S with NAFLD (73\%) than in MET S without NAFLD (47\%) (Fig. 1, Table 4).

HP infection was found more frequent in rural patients than urbans especially in MET $S$ with NAFLD group while age, gender, BMI, and waist circumference showed non-significant difference between both groups (Table 5).

HP infection was significantly higher in patients with marked liver fibrosis using fibrosis risk score [16] in patients having MET S with NAFLD (Table 6). 
Table 1 Demographic characteristics of the studied groups

\begin{tabular}{lllll}
\hline & Total $\boldsymbol{N}=\mathbf{3 0 0}$ & Control $\boldsymbol{N}=\mathbf{1 0 0}$ & Metabolic with NAFLD $\boldsymbol{N}=\mathbf{1 0 0}$ & Metabolic without NAFLD $\boldsymbol{N}=\mathbf{1 0 0}$ \\
\hline Age/years & $47.43 \pm 9.99$ & $47.70 \pm 8.36$ & $47.83 \pm 8.44$ & $46.77 \pm 12.65$ \\
Sex & & & & 54 \\
$\quad$ Male & 176 & 65 & 57 & 46 \\
$\quad$ Female & 124 & 35 & 43 & 85 \\
Residence & & & & 15 \\
Rural & 241 & 77 & 79 & 21 \\
$\quad$ Urban & 59 & 23 & & \\
\hline
\end{tabular}

All parameters described as mean $\pm \mathrm{SD}$, number, and percentage

There were significantly higher values of cholesterol, TGs, ALT, and blood glucose levels in HP positive patients versus HP negative $(P$ value $<0.05)$ while LDL and HDL levels showed non-significant difference (Table 7).

Fibrosis score and the presence of DM (hyperglycemia) were predictors of the HP infection in patients having MET S with NAFLD (Table 8).

\section{Discussion}

Helicobacter pylori (HP) is a Gram-negative microaerophilic bacterium that mainly invades the gastroduodenal wall and can cause inflammation and ulceration up to malignant transformation of the mucosa. It can also cause many intestinal and extra intestinal complications. It was discovered in 1982 and since then its prevalence is increasing and widespread mainly in developing countries [18].
Nonalcoholic fatty liver disease (NAFLD) is one of the most important hepatic diseases that were studied. It is defined as hepatic steatosis in $\geq 5 \%$ of hepatocytes in patients with no or little alcohol intake. It is divided into NAFL or simple steatosis, which often not complicated with cirrhosis or HCC, and nonalcoholic steatohepatitis (NASH) which may progress to complications $[19,20]$.

Insulin resistance is a corner stone in MET $\mathrm{S}$ beside high blood pressure and abnormal cholesterol levels as it is a cluster of metabolic derangements that can lead to many complications including increased risk of DM type II and risk of heart diseases [11]. The main components for diagnosis of MET S are elevated serum triglycerides, elevated blood pressure, fasting blood glucose, increased waist circumference as an indicator for upper body obesity, and decreased high-density lipoproteins levels obtained from the recent accepted consensus [4]. We need 3 or more of these factors for diagnosis.

Table 2 Clinical characteristics among the studied groups

\begin{tabular}{|c|c|c|c|c|c|c|}
\hline & $\begin{array}{l}\text { Total } \\
N=300\end{array}$ & $\begin{array}{l}\text { Control } \\
N=100\end{array}$ & $\begin{array}{l}\text { Metabolic with } \\
\text { NAFLD } N=100\end{array}$ & $\begin{array}{l}\text { Metabolic without } \\
\text { NAFLD } N=100\end{array}$ & $\begin{array}{l}\text { Test of } \\
\text { significance }\end{array}$ & $\begin{array}{l}\text { Within group } \\
\text { significance }\end{array}$ \\
\hline$\overline{\text { Weight }(\mathrm{kg})}$ & $83.22 \pm 17.63$ & $74.35 \pm 9.46$ & $95.80 \pm 23.41$ & $79.51 \pm 6.93$ & $\begin{array}{l}F=54.86 \\
P<0.001^{*}\end{array}$ & $\begin{array}{l}p 1<0.001^{*} \\
p 2=0.016^{*} \\
p 3<0.001^{*}\end{array}$ \\
\hline Height (cm) & $170.21 \pm 10.94$ & $171.92 \pm 8.94$ & $169.87 \pm 13.47$ & $168.84 \pm 9.75$ & $\begin{array}{l}F=2.07 \\
P=0.13\end{array}$ & $\begin{array}{l}p 1=0.18 \\
p 2=0.04^{*} \\
p 3=0.50\end{array}$ \\
\hline $\mathrm{BMI}\left(\mathrm{kg} / \mathrm{m}^{2}\right)$ & $28.91 \pm 7.04$ & $25.28 \pm 3.08$ & $33.18 \pm 10.03$ & $28.28 \pm 2.74$ & $\begin{array}{l}F=40.49 \\
P<0.001^{*}\end{array}$ & $\begin{array}{l}p 1<0.001^{*} \\
p 2<0.001^{*} \\
p 3=0.001^{*}\end{array}$ \\
\hline Waist circumference (cm) & $100.73 \pm 13.40$ & $118.40 \pm 16.27$ & $102.15 \pm 10.51$ & $107.09 \pm 15.75$ & $\begin{array}{l}F=52.12 \\
P<0.001^{*}\end{array}$ & $\begin{array}{l}p 1<0.001^{*} \\
p 2=0.46 \\
p 3=0.001^{*}\end{array}$ \\
\hline Systolic blood pressure (mmHg) & $129.77 \pm 22.64$ & $114.6 \pm 15.0$ & $133.90 \pm 25.30$ & $140.80 \pm 17.6$ & $\begin{array}{l}F=47.06 \\
P<0.001^{*}\end{array}$ & $\begin{array}{l}p 1<0.001^{*} \\
p 2<0.001^{*} \\
p 3=0.01^{*}\end{array}$ \\
\hline Diastolic blood pressure $(\mathrm{mmHg})$ & $82.17 \pm 9.48$ & $75.0 \pm 8.34$ & $84.60 \pm 8.09$ & $86.90 \pm 7.48$ & $\begin{array}{l}F=62.54 \\
P<0.001^{*}\end{array}$ & $\begin{array}{l}p 1<0.001^{*} \\
p 2<0.001^{*} \\
p 3=0.04^{*}\end{array}$ \\
\hline
\end{tabular}

*statistically significant value

$F$ one way ANOVA test, $X^{2}$ Chi-square test, all parameters described as mean $\pm S D$, number and percentage, $p 1$ difference between control and metabolic with NAFLD group, $p 2$ difference between control and metabolic without NAFLD group, $p 3$ difference between metabolic with and without NAFLD 
Table 3 Laboratory parameters among the 3 studied groups

\begin{tabular}{|c|c|c|c|c|c|c|}
\hline & $\begin{array}{l}\text { Total } \\
N=300\end{array}$ & $\begin{array}{l}\text { Control } \\
N=100\end{array}$ & $\begin{array}{l}\text { Metabolic with } \\
\text { NAFLD } N=100\end{array}$ & $\begin{array}{l}\text { Metabolic without } \\
\text { NAFLD } N=100\end{array}$ & $\begin{array}{l}\text { Test of } \\
\text { significance }\end{array}$ & $\begin{array}{l}\text { Within group } \\
\text { significance }\end{array}$ \\
\hline Serum cholesterol (mg/dl) & $148.40 \pm 48.64$ & $94.9 \pm 20.9$ & $183.34 \pm 29.20$ & $166.92 \pm 37.27$ & $\begin{array}{l}F=247.6 \\
P<0.001^{*}\end{array}$ & $\begin{array}{l}p 1=0.001^{*} \\
p 2=0.001^{*} \\
p 3=0.001^{*}\end{array}$ \\
\hline TGS (mg/dl) & 164(50-739) & $100.0(50-300)$ & $204(140-739)$ & $172(110-388)$ & $\begin{array}{l}\text { KW } \\
P<0.001^{*}\end{array}$ & $\begin{array}{l}p 1<0.001^{*} \\
p 2<0.001^{*} \\
p 3<0.001^{*}\end{array}$ \\
\hline LDL (mg/dl) & $98.32 \pm 28.9$ & $88.10 \pm 13.26$ & $108.13 \pm 39.67$ & $98.73 \pm 24.1$ & $\begin{array}{l}F=12.93 \\
P<0.001^{*}\end{array}$ & $\begin{array}{l}p 1=0.001^{*} \\
p 2=0.007^{*} \\
p 3=0.01^{*}\end{array}$ \\
\hline $\mathrm{HDL}(\mathrm{mg} / \mathrm{dl})$ & $40.51 \pm 6.82$ & $44.99 \pm 3.99$ & $36.67 \pm 6.98$ & $39.86 \pm 6.34$ & $\begin{array}{l}F=50.38 \\
P<0.001^{*}\end{array}$ & $\begin{array}{l}p 1<0.001^{*} \\
p 2<0.001^{*} \\
p 3<0.001^{*}\end{array}$ \\
\hline $\mathrm{ALT}(\mathrm{mg} / \mathrm{dl})$ & $40(10-163)$ & $40(30-98)$ & $87(12-163)$ & $50(10-70)$ & $\begin{array}{l}\mathrm{KW} \\
P<0.001^{*}\end{array}$ & $\begin{array}{l}p 1<0.001^{*} \\
p 2<0.001^{*} \\
p 3=0.01^{*}\end{array}$ \\
\hline Fasting blood glucose (mg/dl) & $112(70-500)$ & $80(70-102)$ & $200(70-500)$ & $160(70-436)$ & $\begin{array}{l}\mathrm{KW} \\
P<0.001^{*}\end{array}$ & $\begin{array}{l}p 1<0.001^{*} \\
p 2<0.001^{*} \\
p 3=0.009^{*}\end{array}$ \\
\hline S. creatinine (mg/dl) & $1.08 \pm 0.42$ & $1.124 \pm 0.23$ & $1.10 \pm 0.50$ & $1.02 \pm 0.46$ & $\begin{array}{l}F=1.75 \\
P=0.18\end{array}$ & $\begin{array}{l}p 1=0.68 \\
p 2=0.07 \\
p 3=0.17\end{array}$ \\
\hline
\end{tabular}

*One subject of the control group had TGs level of 300 but it was discovered accidentally by us, and she has no complain and no past medical history that is why she was involved. (Note that all subjects of control group had no past medical history)

NAFLD is considered the hepatic component of metabolic syndrome [21].

There has been speculations regarding the possible association of HP infection and development of NAFLD, which is usually associated with obesity, diabetes, and cardiovascular diseases [22].

This study was conducted to evaluate the possible association between $H$. pylori infection and metabolic syndrome especially with the presence of nonalcoholic fatty liver disease, and to explore if there is a possible role of HP infection in NAFL occurrence and progression especially in the presence of other metabolic abnormalities of MET S.

The study included 300 patients of which metabolic syndrome patients (200 patients) were selected according to recent criteria of Alberti et al. [4] and further

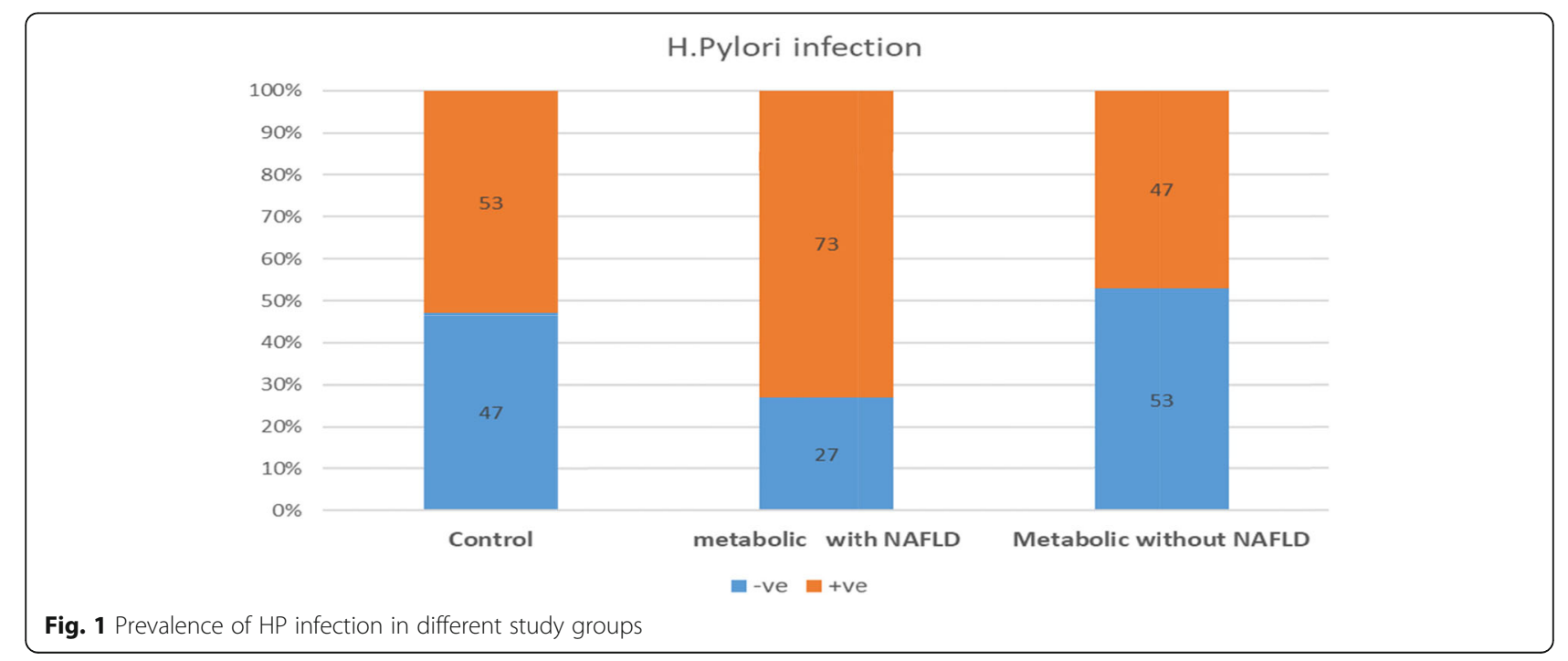


Table $4 \mathrm{H}$. pylori stool Ag results in the studied groups

\begin{tabular}{|c|c|c|c|c|c|c|c|c|c|c|}
\hline & $\begin{array}{l}\text { Tota } \\
N=\end{array}$ & & $\begin{array}{l}\mathrm{Co} \\
N=\end{array}$ & & $\begin{array}{l}\text { Met } \\
\text { NAF }\end{array}$ & $\begin{array}{l}\text { with } \\
=100 \\
\end{array}$ & $\begin{array}{l}\mathrm{Me} \\
\mathrm{NA} \\
\end{array}$ & $\begin{array}{l}\text { ithout } \\
100\end{array}$ & $\begin{array}{l}\text { Test of } \\
\text { significance }\end{array}$ & $\begin{array}{l}\text { Within group } \\
\text { significance }\end{array}$ \\
\hline H. pylori infe & & & & & & & & & & $p 1=0.003^{*}$ \\
\hline Negative & 127 & $42.3 \%$ & 47 & $47 \%$ & 27 & $27 \%$ & 53 & $53 \%$ & $x^{2}=15.18$ & $\begin{array}{l}p 2=0.39 \\
p 3<0.001^{*}\end{array}$ \\
\hline Positive & 173 & $57.7 \%$ & 53 & $53 \%$ & 73 & $73 \%$ & 47 & $47 \%$ & $P=0.001^{*}$ & \\
\hline
\end{tabular}

*statistically significant value

Note that more than half of controls were HP positive that is due to the high prevalence of HP infection in our region. Nevertheless, they had no complain or any history of GIT symptoms

$x^{2}$ Chi-square test, $p 1$ difference between control and metabolic with NAFLD group, $p 2$ difference between control and metabolic without NAFLD group, $p 3$ difference between metabolic with and without NAFLD

subdivided into 2 groups according to the presence or absence of NAFLD, in addition to 100 age-matched healthy controls. All patients were subjected to full history taking and clinical examination laboratory investigations for diagnosis of MET S. All MET S patients had abdominal ultrasonography for detection of hepatic steatosis. NAFLD fibrosis risk score was calculated online for MET S patients with NAFLD to discover patients with marked fibrosis-according to Angulo et al. [16] which divided the patients into NO or mild fibrosis (F0F2) and marked fibrosis (F3-F4) that might progress to NASH. H. pylori stool antigen (SAT) testing was done in all subjects.

Prevalence of HP infection in all study subjects was 57.7\%; this is in agreement with Hooi et al. [23] who reported in their systematic review and meta-analysis that more than half of world population have $H$. pylori infection. Moreover, Eshraghian [13] reported that prevalence of HP infection is increasing in developing countries, and in some areas, it may reach $80 \%$. Also, in our study, rural patients showed significantly higher prevalence of

Table 5 Clinical characteristics of HP positive versus HP negative subjects in MET S with NAFLD group

\begin{tabular}{|c|c|c|c|c|c|}
\hline & \multicolumn{4}{|c|}{ H. pylori infection } & \multirow{2}{*}{$\begin{array}{l}\text { Test of } \\
\text { significance }\end{array}$} \\
\hline & \multicolumn{2}{|c|}{ Negative $n=27$} & \multicolumn{2}{|c|}{ Positive $n=73$} & \\
\hline Age/years & \multicolumn{2}{|c|}{$46.93 \pm 7.77$} & \multicolumn{2}{|c|}{$48.16 \pm 8.70$} & $\begin{array}{l}t=0.65 \\
P=0.52\end{array}$ \\
\hline Sex & $N$ & $\%$ & $N$ & $\%$ & \\
\hline Male & 15 & 55.6 & 42 & 57.5 & $x^{2}=0.03$ \\
\hline Female & 12 & 44.4 & 31 & 42.5 & $P=0.86$ \\
\hline \multicolumn{6}{|l|}{ Residence } \\
\hline Rural & 16 & 59.3 & 63 & 86.3 & $x^{2}=8.688$ \\
\hline Urban & 11 & 40.7 & 10 & 13.7 & $P=0.003^{*}$ \\
\hline BMI $\left(\mathrm{kg} / \mathrm{m}^{2}\right)$ & \multicolumn{2}{|c|}{$33.77 \pm 11.1$} & \multicolumn{2}{|c|}{$32.96 \pm 9.66$} & $\begin{array}{l}t=0.35 \\
P=0.72\end{array}$ \\
\hline Waist circumference & \multicolumn{2}{|c|}{$117.15 \pm 13.94$} & \multicolumn{2}{|c|}{$118.86 \pm 17.12$} & $\begin{array}{l}t=0.47 \\
P=0.64\end{array}$ \\
\hline
\end{tabular}

*statistically significant value

$x^{2}$ Chi-square test
HP infection than urbans especially in MET $\mathrm{S}$ with NAFLD group (Table 5). Muhsen et al. [24] attributed that to low socioeconomic level and bad hygienic conditions which are the major risk factors for intrafamilial transmission of HP infection. Regarding gender differences, some studies showed no difference [25], while others [26] found a male predominance of HP infection in Hyderabad, and Agah et al. [27] found female predominance in HP-induced gastric ulcer. Our study found no gender difference.

In this study, we found that HP infection was more frequent in MET S with NAFLD patients (73\%) than in MET S without NAFLD (47\%) (Table 4), suggesting that HP infection might be associated with the risk of NAFL $\mathrm{D}$ development in those patients. In agreement with our results, Abdel-Razik et al. [28] reported in their study that HP infection increased the risk of NAFLD. Moreover, they suggested that IR, inflammatory mediators, and disturbance in lipid metabolism associated with HP infection are the main mechanisms of NAFLD development. They suggested that eradication of HP might reduce NAFLD risk. In contrast to our study, Okushin et al. [12] reported through logistic regression that HP infection was not associated with NAFLD, that may be due to studying many other variants as BMI, platelet count, and ALT and not focusing on HP infection.

In this study, $60 \%$ of MET S patients were HP positive compared to controls, with statistical significance (Table 4). Other studies [29] found a positive correlation between HP infection and MET S. Moreover, Lim et al. [30] suggested that $H$. pylori infection may play an independent role in the pathogenesis of metabolic syndrome in patients under 65 years old.

Regarding clinical characteristics of the patients, we found significantly higher values of body weight, BMI, and waist circumference in patients having MET $\mathrm{S}$ patients with NAFLD than those without NAFLD (Table 2) which is in agreement with previous studies [12, 31]. Our study shows a statistically significant association between elevated triglycerides, cholesterol, and LDL, and low HDL levels, and NAFLD (Table 3). Also, we found that uncontrolled hyperglycemia is positively associated 
Table 6 Liver fibrosis score among HP positive versus HP negative subjects in MET S with NAFLD group

\begin{tabular}{|c|c|c|c|}
\hline & \multicolumn{2}{|l|}{ H. pylori infection } & \multirow{2}{*}{$\begin{array}{l}\text { Test of } \\
\text { significance }\end{array}$} \\
\hline & Negative $n=27$ & Positive $n=73$ & \\
\hline Mild fibrosis (F0-F2) & 20 )74\%) & $17(23 \%)$ & \multirow{2}{*}{$\begin{array}{l}X^{2}=21.81 \\
P<0.001^{*}\end{array}$} \\
\hline Marked fibrosis (F3-F4) & $7(26 \%)$ & $56(77 \%)$ & \\
\hline
\end{tabular}

*statistically significant value

$x^{2}$ Chi-square test

with NAFLD (Table 3), which is in agreement with previous studies of Friedman et al. [32] who reported that the main metabolic abnormalities predisposing to NAFL D are hyperglycemia, dyslipidemia, IR, and obesity. Also, a positive association between HP infection and elevated S.TGs, cholesterol levels and hyperglycemia was noticed in our study (Table 7).

Regarding the degree of fibrosis in patients of MET S with NAFLD, using fibrosis risk score [16], we found that HP infection is associated with increased degree of fibrosis significantly (Table 6) with progression to marked fibrosis which may complicate with NASH with overall predictive value of $75 \%$ (Table 8) especially in patients with hyperglycemia. That is supported by the study done by Shen et al. [33] who reported that IR resulting from lipid metabolic disturbances and fatty acids accumulation in liver is the main modulator and link between HP infection and hepatic steatosis. Also, the study done by Doğan et al. [34] supports our results as they declared that $H$. pylori infection is strongly linked to the pathogenesis of early-stage NAFLD, which is described as simple steatosis. On the other hand, Polyzos et al. [10] indicated that $H$. pylori infection may not contribute to the progression of NAFL to NASH.
From the previous discussion, it is clear that HP infection is positively associated with occurrence and progression rate of hepatic steatosis (nonalcoholic fatty liver) especially in MET $S$ patients. So, it can be suggested also that testing and eradication of $H$. pylori infection might be indicated in patients having metabolic syndrome which could have a role in decreasing the occurrence as well as the burden of NAFLD in such patients.

However, this study has limitations being a case control study, so further prospective studies are needed to confirm the role of HP in progression of NAFL to $\mathrm{NASH}$ in patients with metabolic syndrome.

\section{Conclusions}

Our study suggested a circle of metabolic abnormalities seemed to be attributed to HP infection in MET S patients increasing the risk of NAFL and progression to marked fibrosis especially with coexistent hyperglycemia, dyslipidemia, and upper body obesity.

HP infection should be kept in mind in patients with MET S. Testing and eradication of HP would help in decreasing metabolic disturbances and possibility of NAFL $\mathrm{D}$, and protect against marked fibrosis progression.

Taking into consideration limitation of this case control study, further prospective longitudinal studies are

Table 7 Lipid profile among patients with HP positive versus HP negative in MET S with NAFLD group

\begin{tabular}{|c|c|c|c|}
\hline & \multicolumn{2}{|l|}{ H. pylori infection } & \multirow{2}{*}{$\begin{array}{l}\text { Test of } \\
\text { significance }\end{array}$} \\
\hline & Negative $n=27$ & Positive $n=73$ & \\
\hline Serum cholesterol & $173.48 \pm 32.63$ & $186.99 \pm 27.17$ & $\begin{array}{l}t=2.09 \\
P=0.03^{*}\end{array}$ \\
\hline TGS & $200.0(140-382)$ & $208(150-739)$ & $\begin{array}{l}z=2.07 \\
P=0.03^{*}\end{array}$ \\
\hline $\mathrm{LDL}$ & $107.19 \pm 44.0$ & $108.48 \pm 38.26$ & $\begin{array}{l}t=0.14 \\
P=0.89\end{array}$ \\
\hline $\mathrm{HDL}$ & $36.26 \pm 5.0$ & $36.82 \pm 7.62$ & $\begin{array}{l}t=0.36 \\
P=0.72\end{array}$ \\
\hline ALT & $25(13-78)$ & $42(12-163)$ & $\begin{array}{l}z=2.28 \\
P=0.02^{*}\end{array}$ \\
\hline AST & $27(12-76)$ & $35(16-107)$ & $\begin{array}{l}z=1.75 \\
P=0.08\end{array}$ \\
\hline Uncontrolled Hyperglycemia & $23(85.2)$ & $72(98.6)$ & $\begin{array}{l}X^{2}=7.50 \\
P=0.006^{*}\end{array}$ \\
\hline
\end{tabular}

*statistically significant value 
Table 8 Predictors of $H$. pylori infection in cases of MET S with NAFLD

\begin{tabular}{llll}
\hline & B & $\boldsymbol{P}$ & Odds ratio $(\mathbf{9 5} \% \mathrm{Cl})$ \\
\hline Fibrosis score & 4.11 & $0.03^{*}$ & $9.54(2.36-25.98)$ \\
DM & 2.26 & $<0.001^{*}$ & $60.94(12.31-80.9)$ \\
Serum cholesterol & 0.009 & 0.34 & $1.01(0.99-1.03)$ \\
TGS & 0.005 & 0.10 & $1.01(0.99-1.01)$ \\
\multicolumn{2}{l}{ Overall \% predicted $=75 \%$} & & \\
\hline
\end{tabular}

*statistically significant value

required to confirm the results and further explore whether early diagnosis and eradication of HP could have an impact on decreasing hepatic complications in those patients side by side with strict control of blood glucose level and follow-up the lipid profile.

Additional research is needed to explore the correlation between HP infection and progression of NAFL to $\mathrm{NASH}$ and/or liver cirrhosis.

\section{Abbreviations}

ALT: Alanine transaminase; AST: Aspartate transaminase; BMI: Body mass index; CVS: Cardiovascular system; HCC: Hepatocellular carcinoma; HDL: High-density lipoprotein; HP: Helicobacter pylori; IR: Insulin resistance. MET S: Metabolic syndrome; NAFLD: Nonalcoholic fatty liver disease; NAFL: Nonalcoholic fatty liver

\section{Acknowledgements}

This manuscript is a part of the MSc Thesis written by Mohamed Rakha, and represents continues, hard, and honest work for 3 successive years of data collection and collaboration between Diabetes \&Endocrinology and Obesity team with Clinical Pathology Department in Faculty of Medicine, Mansoura University.

\section{Authors' contributions}

This study has been carried out as collaboration between all authors. MR reviewed the literature and wrote the study protocol and manuscript draft. OS designed the study, put the hypothesis, revised the written manuscript, and modified the "Results" and "Discussion" parts. MSA checked and revised the manuscript for plagiarism, performed the statistical analysis, and modified the "Background" part of the manuscript. AE supervised and regulated the $H$. pylori test for all subjects, added stool antigen test details, and modified "Methods" part of the manuscript. All authors read and approved the final manuscript.

\section{Funding}

This research did not receive any specific grant from funding agencies in the public, commercial, or not-for-profit sectors.

\section{Availability of data and materials}

The datasets used and/or analyzed during the current study are available from the corresponding author on reasonable request.

\section{Ethics approval and consent to participate}

Written consents from the patients who participated in the study or from their families were obtained, and it was approved by the Mansoura Medical Ethics Committee (MMEC) of the Faculty of Medicine-code number MS.19.03.547

\section{Consent for publication}

Not applicable.

\section{Competing interests}

There are no conflicts of interest.

\section{Author details}

'Department of Internal Medicine, Faculty of Medicine, Mansoura University, Mansoura, Egypt. ${ }^{2}$ Department of Clinical Pathology, Faculty of Medicine, Mansoura University, Mansoura, Egypt.

Received: 16 July 2020 Accepted: 14 December 2020

Published online: 22 January 2021

\section{References}

1. Eslick GD, Lim LL, Byles JE, Xia HH, Talley NJ (1999) Association of Helicobacter pylori infection with gastric carcinoma: a meta-analysis. Am J Gastroenterol 94(9):2373-2379. https://doi.org/10.1111/j.1572-0241.1999. 01360.x

2. Schistosomes, liver flukes and Helicobacter pylori. IARC Working Group on the Evaluation of Carcinogenic Risks to Humans. Lyon, 7-14 June 1994. (1994). IARC monographs on the evaluation of carcinogenic risks to humans. World Health Organization, International Agency for Research on Cancer, 61, 1-241. Retrieved from http://www.ncbi.nlm.nih.gov/pubmed/ 7715068

3. Sonnenberg A, Genta RM (2013) Helicobacter pylori is a risk factor for colonic neoplasms. Am J Gastroenterol 108(2):208-215. https://doi.org/10.1038/ajg. 2012.407

4. Alberti KGMM, Eckel RH, Grundy SM, Zimmet PZ, Cleeman Jl, Donato KA, Fruchart J-C, James WPT, Loria CM, Smith SC (2009) Harmonizing the metabolic syndrome. Circulation 120(16):1640-1645. https://doi.org/10.1161/ circulationaha.109.192644

5. Radaelli MG, Martucci F, Perra S, Accornero S, Castoldi G, Lattuada G et al (2018) NAFLD/NASH in patients with type 2 diabetes and related treatment options. J Endocrinoll Investig 41(5):509-521. https://doi.org/10.1007/ s40618-017-0799-3

6. Wong RJ, Aguilar M, Cheung R, Perumpail RB, Harrison SA, Younossi ZM, Ahmed A (2015) Nonalcoholic steatohepatitis is the second leading etiology of liver disease among adults awaiting liver transplantation in the United States. Gastroenterology 148(3):547-555. https://doi.org/10.1053/j.gastro. 2014.11.039

7. Dixon JB, Bhathal PS, Hughes NR, O'Brien PE (2004) Nonalcoholic fatty liver disease: improvement in liver histological analysis with weight loss. Hepatology (Baltimore, Md.) 39(6):1647-1654. https://doi.org/10.1002/hep. 20251

8. Cindoruk M, Cirak MY, Unal S, Karakan T, Erkan G, Engin D et al (2008) Identification of Helicobacter species by 165 rDNA PCR and sequence analysis in human liver samples from patients with various etiologies of benign liver diseases. Eur J Gastroenterol Hepatol 20(1):33-36. https://doi. org/10.1097/MEG.0b013e3282efa4f2

9. Pirouz T, Zounubi L, Keivani H, Rakhshani N, Hormazdi M (2009) Detection of Helicobacter pylori in paraffin-embedded specimens from patients with chronic liver diseases, using the amplification method. Dig Dis Sci 54(7): 1456-1459. https://doi.org/10.1007/s10620-008-0522-5

10. Polyzos SA, Kountouras J, Papatheodorou A, Patsiaoura K, Katsiki E, Zafeiriadou E et al (2013) Helicobacter pylori infection in patients with nonalcoholic fatty liver disease. Metabolism 62(1):121-126. https://doi.org/ 10.1016/j.metabol.2012.06.007

11. Mendrick DL, Diehl AM, Topor LS, Dietert RR, Will Y, La Merrill MA, Bouret S, Varma V, Hastings KL, Schug TT, Emeigh Hart SG, Burleson FG (2017) Metabolic syndrome and associated diseases: from the bench to the clinic. Toxicol Sci 162(1):36-42. https://doi.org/10.1093/toxsci/kfx233D

12. Okushin K, Takahashi Y, Yamamichi N, Shimamoto T, Enooku K, Fujinaga H et al (2015) Helicobacter pylori infection is not associated with fatty liver disease including non-alcoholic fatty liver disease: a large-scale crosssectional study in Japan. BMC Gastroenterol 15(1):25. https://doi.org/10. 1186/s12876-015-0247-9

13. Eshraghian A (2014) Epidemiology of Helicobacter pylori infection among the healthy population in Iran and countries of the Eastern Mediterranean Region: a systematic review of prevalence and risk factors. World J Gastroenterol 20(46):17618-17625. https://doi.org/10.3748/wjg.v20.i46.17618

14. Babusik P, Bilal M, Duris I (2011) Nonalcoholic fatty liver disease of two ethnic groups in Kuwait: comparison of prevalence and risk factors. Med Princ Pract 21(1):56-62. https://doi.org/10.1159/000331591

15. Van Werven JR, Marsman HA, Nederveen AJ, Smits NJ, Ten Kate FJ, Van Gulik TM, Stoker J (2010) Assessment of hepatic steatosis in patients undergoing liver resection: comparison of US, CT, T1-weighted dual-echo 
MR imaging, and point-resolved 1H MR spectroscopy. Radiology 256(1):159168. https://doi.org/10.1148/radiol.10091790

16. Angulo P, Hui JM, Marchesini G, Bugianesi E, George J, Farrell GC et al (2007) The NAFLD fibrosis score: a noninvasive system that identifies liver fibrosis in patients with NAFLD. Hepatology 45(4):846-854. https://doi.org/ 10.1002/hep.21496

17. Leal YA, Cedillo-Rivera R, Simón JA, Velázquez JR, Flores LL, Torres J (2011) Utility of stool sample-based tests for the diagnosis of Helicobacter pylori infection in children. J Pediatr Gastroenterol Nutr 52(6):718-728. https://doi. org/10.1097/MPG.0b013e3182077d33

18. Burucoa C, Axon A (2017) Epidemiology of Helicobacter pylori infection. Helicobacter 22:e12403. https://doi.org/10.1111/hel.12403

19. de Alwis NMW, Day CP (2008) Non-alcoholic fatty liver disease: the mist gradually clears. J Hepatol 48:S104-S112. https://doi.org/10.1016/j.jhep.2008.01.009N

20. Bhala N, Jouness R, Bugianesi E (2013) Epidemiology and natural history of patients with NAFLD. Curr Pharm Des 19(29):5169-5176. https://doi.org/10. 2174/13816128113199990336N

21. Chalasani N, Younossi Z, Lavine JE, Diehl AM, Brunt EM, Cusi K et al (2012) The diagnosis and management of non-alcoholic fatty liver disease: practice guideline by the American Association for the Study of Liver Diseases, American College of Gastroenterology, and the American Gastroenterological Association. Hepatology 55(6):2005-2023. https://doi.org/10.1002/hep.25762

22. Chen C, Zhang C, Wang X, Zhang F, Zhang Z, Ma P, Feng S (2019) Helicobacter pylori infection may increase the severity of nonalcoholic fatty liver disease via promoting liver function damage, glycometabolism, lipid metabolism, inflammatory reaction and metabolic syndrome. Eur J Gastroenterol Hepatol. https://doi.org/10.1097/MEG.0000000000001601

23. Hooi JKY, Lai WY, Ng WK, Suen MMY, Underwood FE, Tanyingoh D et al (2017) Global prevalence of Helicobacter pylori infection: systematic review and meta-analysis. Gastroenterology 153(2):420-429. https://doi.org/10.1053/ j.gastro.2017.04.022

24. Muhsen K, Athamna A, Athamna M, Spungin-Bialik A, Cohen D (2006) Prevalence and risk factors of Helicobacter pylori infection among healthy 3to 5-year-old Israeli Arab children. Epidemiol Infect 134(5):990-996. https:// doi.org/10.1017/S0950268806006030

25. Cover TL, Blaser MJ (2009) Helicobacter pylori in health and disease. Gastroenterology 136(6):1863-1873. https://doi.org/10.1053/.jgastro.2009.01.073

26. Ahmed KS \& Ahmed Khan, A. (2014). Functional characterization of Mycobacterium tuberculosis DosR regulon genes view project endonucleases in H. pylori view project. Retrieved from https://www. researchgate.net/publication/7207648

27. Agah S, Khedmat H, Ghamar-Chehred ME, Hadi R, Aghaei A (2016) Female gender and Helicobacter pylori infection, the most important predisposition factors in a cohort of gastric cancer: a longitudinal study. Caspian J Int Med 7(2):136-141

28. Abdel-Razik A, Mousa N, Shabana W, Refaey M, Elhelaly R, Elzehery R et al (2018) Helicobacter pylori and non-alcoholic fatty liver disease: a new enigma? Helicobacter 23(6):e12537. https://doi.org/10.1111/hel.12537

29. Rasmi Y, Seyyed-Mohammadzad MH (2012) Frequency of Helicobacter pylori and cytotoxine associated gene A antibodies in patients with cardiac syndrome X. J Cardiovasc Dis Res 3(1):19-21. https:/doi.org/10.4103/0975-3583.91597

30. Lim SH, Kim N, Kwon JW, Kim SE, Baik GH, Lee JY et al (2019) Positive association between Helicobacter pylori infection and metabolic syndrome in a Korean population: a multicenter nationwide study. Dig Dis Sci. https:// doi.org/10.1007/s10620-019-05544-3

31. Liu M, Wang J, Zeng J, Cao X, He Y (2017) Association of NAFLD with diabetes and the impact of BMl changes: a 5-year cohort study based on 18,507 elderly. J Clin Endocrinol Metab 102(4):1309-1316. https://doi.org/10.1210/jc.2016-3440M

32. Friedman SL, Neuschwander-Tetri BA, Rinella M, Sanyal AJ (2018) Mechanisms of NAFLD development and therapeutic strategies. Nat Med 24:908-922. https://doi.org/10.1038/s41591-018-0104-9

33. Li M, Shen Z, Li YM (2013) Potential role of Helicobacter pylori infection in nonalcoholic fatty liver disease. World I Gastroenterol 19:7024-7031. https:// doi.org/10.3748/wjg.v19.141.7024

34. Doğan Z, Filik L, Ergül B, Sarikaya M, Akbal E (2013) Association between Helicobacter pylori and liver-to-spleen ratio. Eur J Gastroenterol Hepatol 25(1):107-110. https://doi.org/10.1097/meg.0b013e3283590c10Z

\section{Publisher's Note}

Springer Nature remains neutral with regard to jurisdictional claims in published maps and institutional affiliations.

\section{Submit your manuscript to a SpringerOpen ${ }^{\circ}$ journal and benefit from:}

- Convenient online submission

- Rigorous peer review

- Open access: articles freely available online

- High visibility within the field

- Retaining the copyright to your article

Submit your next manuscript at $\boldsymbol{\nabla}$ springeropen.com 